\title{
Detailed geometry of the subducting Indian Plate beneath the Burma Plate and subcrustal seismicity in the Burma Plate derived from joint hypocenter relocation
}

\author{
Nobuo Hurukawa ${ }^{1}, \mathrm{~Pa} \mathrm{~Pa} \mathrm{Tun}^{2}$, and Bunichiro Shibazaki ${ }^{1}$ \\ ${ }^{1}$ International Institute of Seismology and Earthquake Engineering (IISEE), Building Research Institute, Tsukuba, Ibaraki 305-0802, Japan \\ ${ }^{2}$ Department of Meteorology and Hydrology, Ministry of Transport, Nay Pyi Taw, Myanmar
}

(Received May 20, 2011; Revised October 17, 2011; Accepted October 31, 2011; Online published May 25, 2012)

\begin{abstract}
With the aim of delineating the subducting Indian Plate beneath the Burma Plate, we have relocated earthquakes by employing teleseismic $P$-wave arrival times. We were able to obtain the detailed geometry of the subducting Indian Plate by constructing iso-depth contours for the subduction earthquakes at depths of 30-140 km. The strikes of the contours are oriented approximately N-S, and show an "S" shape in map view. The strike of the slab is $\mathrm{N} 20^{\circ} \mathrm{E}$ at $25^{\circ} \mathrm{N}$, but moving southward, the strike rotates counterclockwise to $\mathrm{N} 20^{\circ} \mathrm{W}$ at $20^{\circ} \mathrm{N}$, followed by a clockwise rotation to a strike of $\mathrm{N} 10^{\circ} \mathrm{E}$ at $17.5^{\circ} \mathrm{N}$, where slab earthquakes no longer occur. The plate boundary north of $20^{\circ} \mathrm{N}$ might exist near, or west, of the coast line of Myanmar. The mechanisms of subduction earthquakes are down-dip extension, and $T$ axes are oriented parallel to the local dip of the slab. Subcrustal seismicity occurs at depths of $20-50 \mathrm{~km}$ in the Burma Plate. This activity starts near the $60-\mathrm{km}$-depth contour of the subduction earthquakes and becomes shallower toward the Sagaing Fault, indicating that this fault is located where the cut-off depth of the seismicity becomes shallower.
\end{abstract}

Key words: Burma Plate, Indian Plate, subduction, relocation, joint hypocenter determination.

\section{Introduction}

Myanmar, situated within the Alpine Himalayan earthquake belt, is one of the most earthquake-prone countries in the world. There exist four tectonic plates in and around Myanmar: the Indian, Eurasian, Burma, and Sunda Plates (Fig. 1). The relative motion between the Indian and Eurasian Plates is about $5 \mathrm{~cm} / \mathrm{yr}$, oriented toward $\sim \mathrm{N} 20^{\circ} \mathrm{E}$ in Myanmar (DeMets et al., 1994). Therefore, the Indian Plate is subducting beneath the Indochina Peninsula, including the Burma Plate, along the Sunda and Andaman trenches with a highly oblique convergence; in this setting, the Burma Plate represents a fore-arc sliver that is coupled with the Indian Plate (e.g., Satyabala, 2003; Nielsen et al., 2004; Stork et al., 2008). An eastward-dipping WadatiBenioff zone extends to about $180-\mathrm{km}$ depth, and the majority of intermediate-depth earthquakes have east-trending down-dip $T$ axes and along-strike $P$ axes (e.g., Fitch, 1970; Frohlich, 2006). Therefore, these earthquakes occurred not along the plate boundary, but within the subducting Indian Plate, reflecting its negative buoyancy or slab pull.

The maximum depth of intermediate-depth earthquakes becomes shallower when passing southward into southern Myanmar. Southward from here, no intermediatedepth earthquakes occur in the area between the Andaman Islands and Myanmar (e.g., Sinvhal et al., 1978; Rajendran and Gupta, 1989; Guzman-Speziale and Ni,

Copyright (C) The Society of Geomagnetism and Earth, Planetary and Space Sciences (SGEPSS); The Seismological Society of Japan; The Volcanological Society of Japan; The Geodetic Society of Japan; The Japanese Society for Planetary Sciences; TERRAPUB.

doi:10.5047/eps.2011.10.011
1996). Intermediate-depth earthquakes reappear farther south, as is clear from the existence of aftershocks of the 2004 Sumatra Andaman earthquake, which was a subduction earthquake (e.g., Engdahl et al., 2007).

The Sagaing Fault is one of the most prominent, active strike-slip faults in Myanmar, extending for over 1,000 km from north to south, and connecting with the Andaman spreading center at its southern termination (Fig. 1). Historical records indicate that large earthquakes have occurred along the Sagaing Fault (e.g., Hurukawa and Maung, 2011). The largest earthquake to have occurred along, or near, the Myanmar portion of this fault is the $M_{\mathrm{w}} 8,1912$, Burma earthquake. $M$ 7-class earthquakes occurred in 1930, 1988, 1991, and 1992, causing damage in Myanmar. The Sagaing Fault has been interpreted as the plate boundary between the Burma and Sunda Plates (e.g., Le Dain et al., 1984; Guzman-Speziale and Ni, 1996). Therefore, in order to understand the tectonics of Myanmar, it is necessary to determine the relative motion between these plates. The motions of these plates were recently determined by global positioning system (GPS) observations (Vigny et al., 2003; Socquet et al., 2006). According to Socquet et al. (2006), the relative motion between the India and Sunda Plates is $35 \mathrm{~mm} / \mathrm{yr}$ toward $\mathrm{N} 10^{\circ} \mathrm{E}$, and strike-slip motion along the Sagaing Fault accommodates displacement at a rate of $18 \mathrm{~mm} / \mathrm{yr}$, which is only half of the shear component of motion. The remaining deformation may be explained either by convergence at the Burma (or Arakan) subduction zone, or localized deformation west of the Sagaing Fault. The rate and direction of convergence are $23 \mathrm{~mm} / \mathrm{yr}$ and $\mathrm{N} 35^{\circ} \mathrm{E}$, respectively, in the 


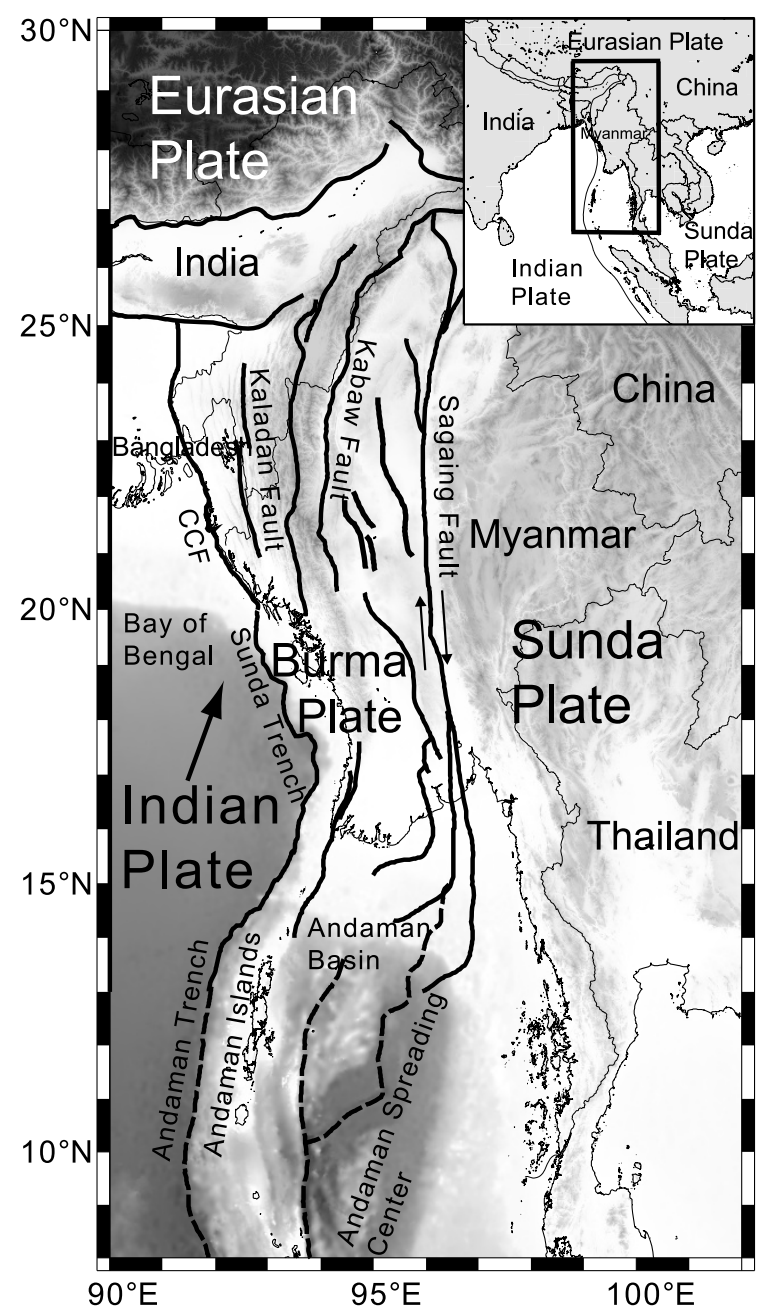

Fig. 1. Regional map showing the tectonic setting of the present study. Locations of faults and trenches are taken from Nielsen et al. (2004), although the Chittagong Coastal Fault (CCF) is taken from Maurin and Rangin (2009). The thick arrow indicates the relative motion between the Indian and Eurasian Plates (DeMets et al., 1994).

case that deformation is localized along the Burma subduction zone (Socquet et al., 2006).

Cummins (2007) noted the high likelihood of the occurrence of a tsunamigenic earthquake in the northern Bay of Bengal along the Burma subduction zone. This prediction was based mainly on the coupling of the plate interface and the generation of a tsunami following the 1762 Arakan earthquake. Since this earlier study did not consider seismic data which indicates the geometry of the plate interface, it is necessary to investigate the detailed geometry of the subducting Indian Plate using precise hypocenter locations. Gupta and Gahalaut (2009) examined Cummins' (2007) proposal regarding the likelihood of a tsunamigenic earthquake, and concluded that a great earthquake in the Arakan region is unlikely to result in a large tsunami.

To understand the geometry of the subduction interface and the seismic activity, it is necessary to acquire detailed information on the hypocenter locations. However, hypocenters have been poorly determined in the area around Myanmar, because there exists no local seismic network. Ni et al. (1989) and Guzman-Speziale and Ni (1996) obtained the surface projection of the geometry of the subducting In- dian Plate from $60 \mathrm{~km}$ to 120 or $140 \mathrm{~km}$ using hypocenters reported by the International Seismological Centre (ISC). Relocating hypocenters using the joint hypocenter determination (JHD) method, Stork et al. (2008) also obtained the geometry of the subducting Indian Plate north of $21^{\circ} \mathrm{N}$. The results of these studies do not support Cummins's (2007) proposal regarding subduction earthquakes in the Bay of Bengal, because their results are consistent with their assumption that the plate boundary occurs on land, north of $20^{\circ} \mathrm{N}$, at the approximate location of the Kaladan Fault (Fig. 1).

The purpose of the present study is to relocate hypocenters using global data with the aim of obtaining the precise geometry of the subducting Indian Plate and to understand the tectonic features of Myanmar, because no local or regional networks are available in Myanmar. Although a topic of discussion, there exists a high likelihood of large tsunamigenic earthquakes along the Burma subduction zone (e.g., Cummins, 2007) and of inland earthquakes along the Sagaing Fault. Therefore, a current research priority is to determine the location of the subduction interface and the precise locations of inland earthquakes.

\section{Method}

To precisely relocate hypocenters, we employed the modified joint hypocenter determination (MJHD) method developed by Hurukawa and Imoto $(1990,1992)$. Because of the lateral heterogeneity of the Earth, the assumption of the horizontally homogeneous velocity model, which is normally used in hypocenter determination, is inadequate to obtain the precise location of earthquakes. The joint hypocenter determination (JHD) method (Douglas, 1967; Freedman, 1967; Dewey, 1972) enables us to simultaneously relocate many earthquakes, thereby removing the effects of the lateral heterogeneity within the Earth. We define therefore a station correction to account for the lateral heterogeneity of the Earth. However, given the heterogeneous nature of the Earth's structure and in cases of poor station coverage, JHD solutions become unstable and unreliable as a result of the trade-off between station corrections and the focal depths of earthquakes. For this reason, Hurukawa and Imoto (1990, 1992) developed the MJHD method for locating local earthquakes, in which the station correction (SC) is independent of both the distance and azimuth from the center of the studied region to a given station, thereby improving the stability of the method. These priors make absolute values of SCs smaller, and MJHD locations then become closer to locations by the single-event method on average. The numerical technique used in the MJHD method is based on Householder's QR orthogonal reduction, which is the same as the method used by Smith (1982) except for the four additional equations on station corrections. Subsequently, Hurukawa (1995) extended the MJHD method for locating teleseismic earthquakes, and we use this extended version in the present study, in which we use the iasp91 travel-time table in the calculation of travel times. Since we have used teleseismic data in this study, it is simply not possible to improve the absolute location accuracy, largely because of the lateral heterogeneity in the Earth. Standard errors of hypocenters calculated in this study do not represent absolute errors of 
hypocenters. However, we have been able to improve the accuracy of relative locations significantly.

\section{Data}

To obtain precise hypocenter locations using the MJHD method, it is better to consider a small region with no significant horizontal variation in structure. In this regard, the study area can be divided into three regions: (A) the Burma subduction zone, (B) the region from the Burma subduction zone to the Sagaing Fault, and $(C)$ the back-arc opening region. In the case of strong lateral heterogeneity in the velocity structure, station correction becomes highly dependent on the location of earthquakes. Accordingly, for the purposes of analysis, we identified several sub-regions in each of the three regions described above (Fig. 2). The sizes of the sub-regions are as follows: sub-regions A1 to A4: $1^{\circ} \times 4^{\circ}$; sub-regions A5 to A7, and B1 to B4: $2^{\circ} \times 4^{\circ}$; and sub-region $\mathrm{C} 1: 4^{\circ} \times 4^{\circ}$. Note that three of the subregions (A5-A7) overlap with the three neighboring subregions $(\mathrm{B} 3, \mathrm{~B} 4$, and $\mathrm{C} 1)$ in order to increase the number of earthquakes in each sub-region and to evaluate the location errors.

We used data from the International Seismological Centre (ISC) for the period 1964-2004, and from the United States Geological Survey (USGS) for the period 20052007. We used only $P$-wave first arrival times, because the phase data for the initial $P$-wave arrival times are much

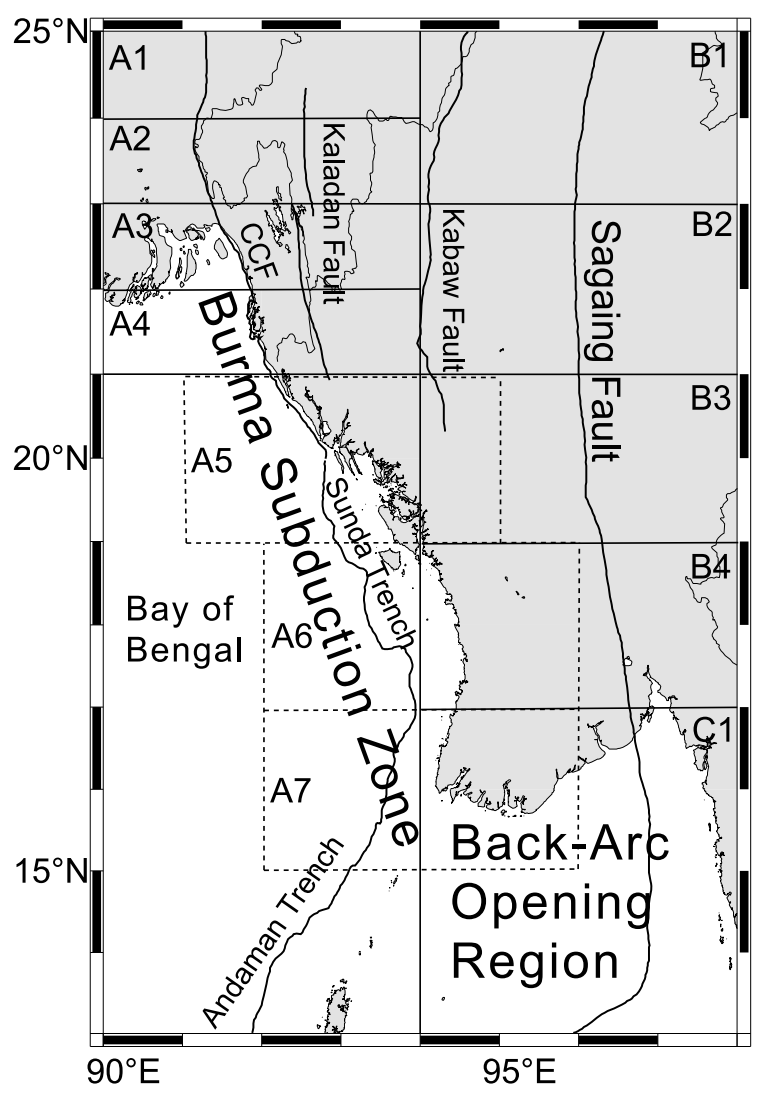

Fig. 2. Map showing the 3 regions and 12 sub-regions analyzed in this study. The three regions are (1) the Burma subduction zone (sub-regions A1-A7), (2) the area from the Burma subduction zone to the Sagaing Fault (sub-regions B1-B4), and the back-arc opening zone (sub-region C1). more accurate than those for $S$-wave arrival times. Let's examine the reading accuracies of $P$ - and $S$-wave arrival times in sub-region A1, for example. The ISC reported 153 events and calculated travel-time residuals $(\mathrm{O}-\mathrm{C})$ for all readings. For $P$ waves, $77 \%$ and $90 \%$ of all 8,199 readings are $|\mathrm{O}-\mathrm{C}|<2 \mathrm{~s}$ and $4 \mathrm{~s}$, respectively. While for $S$ waves, $28 \%$ and $47 \%$ of all 1,520 readings are $|\mathrm{O}-\mathrm{C}|<2 \mathrm{~s}$ and $4 \mathrm{~s}$, respectively. These facts indicate how $S$ readings are worth than $P$ readings. Phase data for which the travel-time residuals exceeded $3 \mathrm{~s}$ were not considered in the calculation.

To calculate the hypocenters, two parameters must be defined: the minimum number of stations (MSTN) that observed each earthquake, and the minimum number of earthquakes (MEVN) observed at each station for each subregion. Here, MSTN and MEVN were set to 15 and 15, respectively, except in the case of some sub-regions. During the relocation process, we removed readings having large travel-time residuals. Then, numbers of used stations at some stations may become less than MEVN. However, we continued using these stations in order not to remove valuable nearby stations, as they contributed to obtaining reliable absolute locations.

\section{Results}

We relocated 980 earthquakes within the 12 sub-regions, for which the standard errors of latitude, longitude, and depth were less than $0.1^{\circ}, 0.1^{\circ}$, and $20 \mathrm{~km}$, respectively, and for which the epicentral distance from the nearest station was less than $14^{\circ}$. Standard errors of the focal depths of 623 events $(63.6 \%)$ and 859 events $(87.7 \%)$ among the 980 events are less than $5 \mathrm{~km}$ and $10 \mathrm{~km}$, respectively. While Standard errors of latitude and longitude of 834 events $(85.1 \%)$ and 872 events $(89.0 \%)$ among 980 events are less than $0.05^{\circ}$, respectively. The smallest magnitude is 3.4 , while the cut-off magnitude of the Gutenberg-Richter relation is $\sim 5.0$.

The number of stations used in each sub-region was 65 to 391. Stations at each sub-region distributed around the source region including India, China, Indochina, and Australia.

To demonstrate how the locations were improved compared with catalog locations, we consider the result for subregion A1 as an example. Sub-region A1 is located in the northern part of the Burma subduction zone, close to the collision region in the north (Figs. 1 and 2). The original ISC and USGS catalogs contain 161 earthquakes in this sub-region (Fig. 3(a)). Sixty earthquakes among them were located using 117 worldwide stations (Fig. 4). Figures 3(b) and 3(c) show the hypocenter distribution determined by ISC and USGS, and that determined in the present study using the MJHD method, respectively. Only 57 well-located earthquakes are shown in the figures, for which the standard errors of latitude, longitude, and depth are less than $0.1^{\circ}$, $0.1^{\circ}$, and $20 \mathrm{~km}$, respectively. Although crustal earthquakes could not be distinguished from subduction earthquakes, based on catalog locations, this was possible with reference to the relocated hypocenters. It is clear from Figs. 3(b) and 3(c) that there is no bias in the MJHD locations.

After relocation, many of the hypocenters are concentrated in small areas. Subcrustal and intermediate-depth 

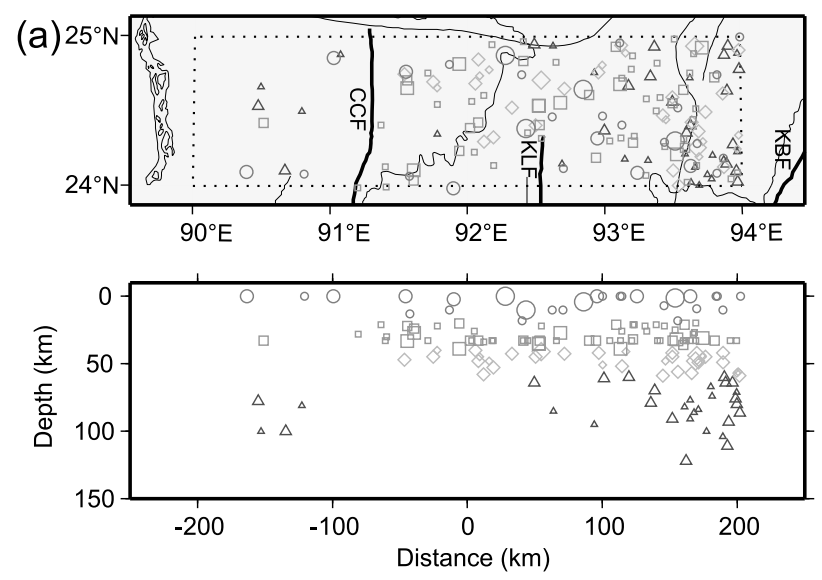

(b)
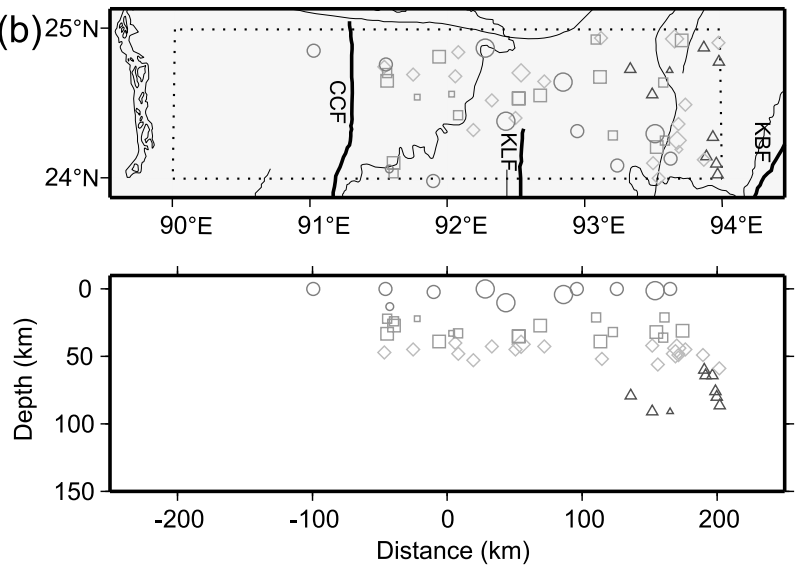

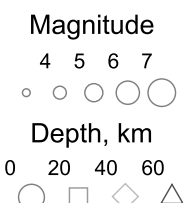

(c)
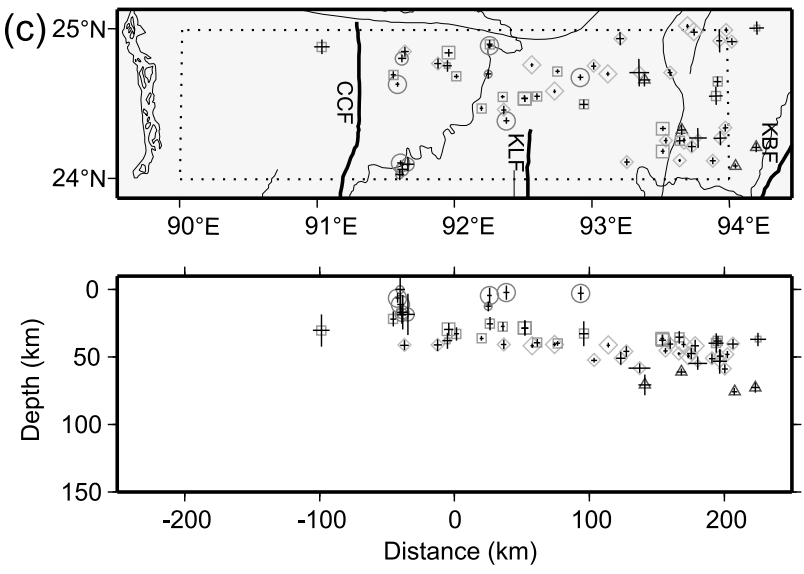

Fig. 3. Epicentral distribution in sub-region A1 of the Burma subduction zone, and E-W vertical cross-sections. Symbol size represents earthquake magnitude; symbol shape denotes the depth. The dotted rectangle in the epicentral maps indicates the epicentral area of selected earthquakes. (a) Hypocenters located by ISC and USGS (1964-2007). (b) Selected ISC and USGS hypocenters. Only those earthquakes also shown in Fig. 3(c) are plotted here. (c) Hypocenters relocated using the MJHD method. The bars represent the standard errors of the hypocenter locations. The earthquakes shown are those with precise hypocenters, for which the standard errors of latitude, longitude, and focal depth are less than $0.1^{\circ}, 0.1^{\circ}$, and $20 \mathrm{~km}$, respectively. CCF: Chittagong Coastal Fault. KLF: Kaladan Fault. KBF: Kabaw Fault. Note that magnitude is expressed as $m_{\mathrm{b}}$ (by ISC and USGS).

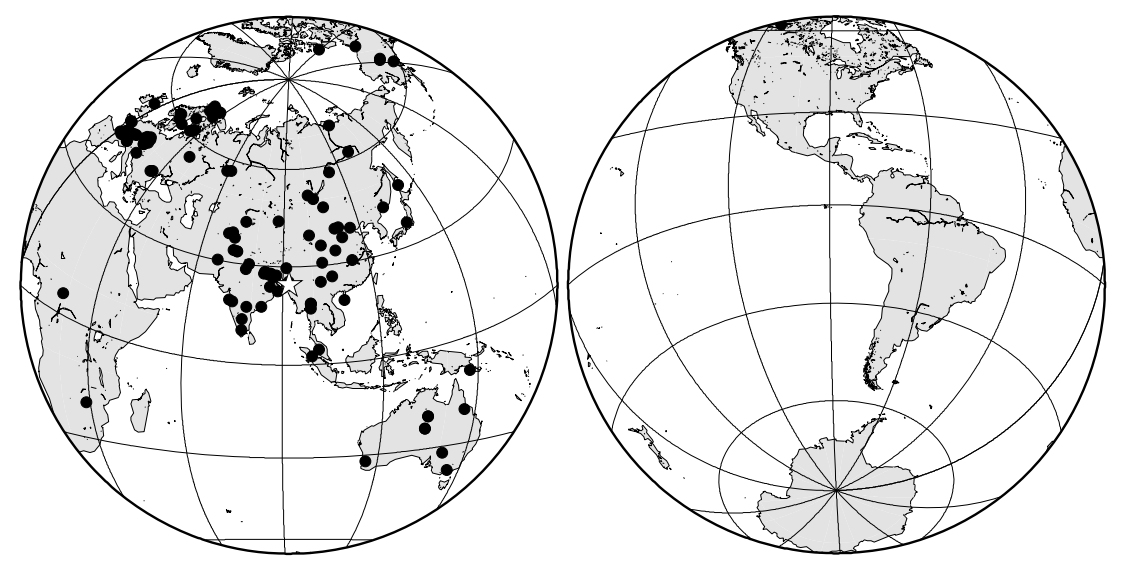

Fig. 4. Distribution of stations used for relocations in sub-region A1. The star indicates the center of the sub-region.

earthquakes, which occur at depths of $\sim 30 \mathrm{~km}$ or more, were well relocated along a thin seismic layer. The layer is sub-horizontal and slightly dipping eastward, corresponding to the boundary between the subducting Indian Plate and the overriding Burma Plate. Note that the results for other sub-regions (except for B1) are shown in Tun (2008). Between 34 and 293 earthquakes were well relocated in each sub-region in our study.
Combining the hypocenters relocated in all sub-regions, we have created a catalog of relocated earthquakes in the study region. Note that there are overlapping areas between sub-regions A5 and B3, A6 and B4, and A7 and C1 (see Fig. 2). Consequently, in some cases, earthquakes were relocated in both sub-regions. In such cases, we selected and plotted earthquakes relocated in the eastern sub-regions (i.e., B3, B4, and C1); duplicated earthquakes relocated 


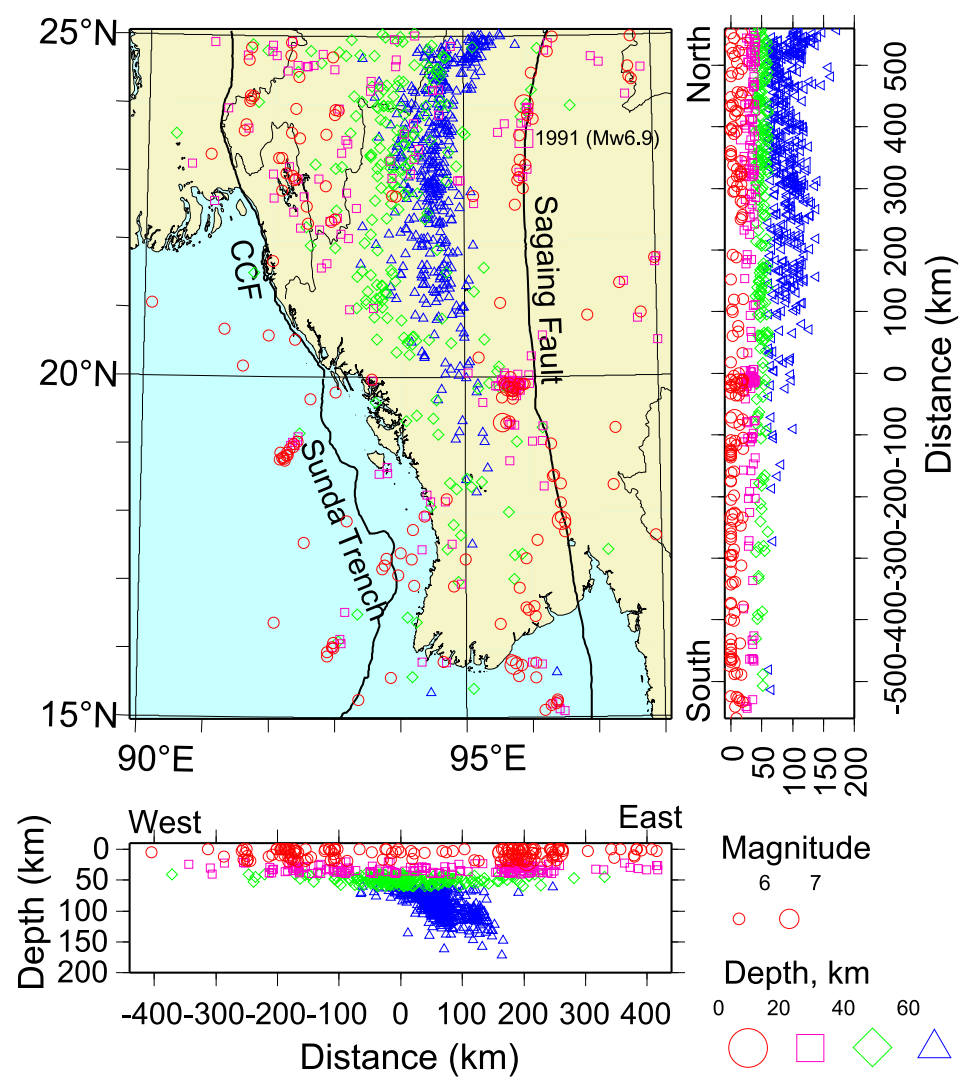

Fig. 5. Epicentral distribution, and E-W and N-S cross-sections, of relocated earthquakes in the Burma subduction zone and the area around the Sagaing Fault. Only earthquakes with precise hypocenters are shown, for which the standard errors of latitude, longitude, and focal depth are less than $0.1^{\circ}$, $0.1^{\circ}$, and $20 \mathrm{~km}$, respectively, and for which the epicentral distance from the nearest stations is less than $14^{\circ}$.

in the western sub-regions were not included in the catalog. This approach was adopted because more earthquakes were relocated in the eastern sub-regions than in the western sub-regions. Although the hypocenters in the overlap areas between adjacent sub-regions may differ for a given earthquake, this difference is relatively small: for the 75 earthquakes in the overlap areas, the average and standard deviation of the differences (between the eastern and western sub-regions) in latitude, longitude, and focal depth for each earthquake are $-0.006^{\circ} \pm 0.064^{\circ}, 0.022^{\circ} \pm 0.053^{\circ}$, and $2.40 \pm 7.06 \mathrm{~km}$, respectively. Furthermore, there is no directional bias in the differences. For comparison, the average and standard errors (in latitude, longitude, and focal depth) for the 75 relocated earthquakes in the eastern sub-regions are $0.033^{\circ} \pm 0.016^{\circ}, 0.027^{\circ} \pm 0.013^{\circ}$, and $4.8 \pm 2.8 \mathrm{~km}$, respectively. Therefore, the average differences between the two locations are less than the standard errors of hypocenter locations. Consequently, we conclude that no systematic bias has been introduced in the new catalog. In the following sections, we outline the main features of the seismicity.

\section{Detailed Geometry of the Subducting Indian Plate beneath the Burma Plate}

Figure 5 shows the epicentral distribution, and the E$\mathrm{W}$ and N-S cross-sections, of relocated earthquakes in the Burma subduction zone, including the Sagaing Fault. It is clear that the focal depths of earthquakes are related to the subduction of the Indian Plate, becoming deeper eastward until $\sim 95^{\circ} \mathrm{E}$, about $1^{\circ}$ west of the Sagaing Fault. The maximum depth of the hypocenters shows a gradual decrease southward. To determine the geometry of the subducting Indian Plate, we plotted the relocated earthquakes on the E-W cross-sections (Fig. 6). On the cross-sections, the earthquake locations are plotted at $0.5^{\circ}$ intervals in latitude. The majority of earthquakes are intermediate-depth and subcrustal earthquakes, at depths of $\sim 30 \mathrm{~km}$ or greater, defining a thin east-dipping seismic layer, distinct from crustal earthquakes. In particular, the earthquakes are concentrated along a surprisingly thin zone at depths of 40$120 \mathrm{~km}$ between $21.0^{\circ} \mathrm{N}$ and $22.5^{\circ} \mathrm{N}$ (Figs. 6(f), 6(g), and $6(\mathrm{~h})$ ), with an apparent thickness of the seismic layer of less than $20 \mathrm{~km}$.

Based on the epicentral distribution (Fig. 5) and the depth cross-sections (Fig. 6), we constructed iso-depth contours for the upper surface of the seismic plane, as shown in Fig. 7. Since the depths of subduction earthquakes change smoothly in space, we could draw the iso-depth contours smoothly without discontinuities or rapid changes in strike and dip of the surface. Note that, because there exists no direct evidence regarding the actual depth and geometry of the plate interface, the iso-depth contours represent the maximum possible depth of the slab surface, which might be a few to $\sim 10 \mathrm{~km}$ beneath the upper surface of the subducting Indian Plate. This is because the mechanism of subduction earthquakes is down-dip extension, which indicates that they occurred not along the plate interface but inside the subducting plate. We constructed iso-depth contours at $20-\mathrm{km}$ intervals between depths of 40 and $140 \mathrm{~km}$. We also 

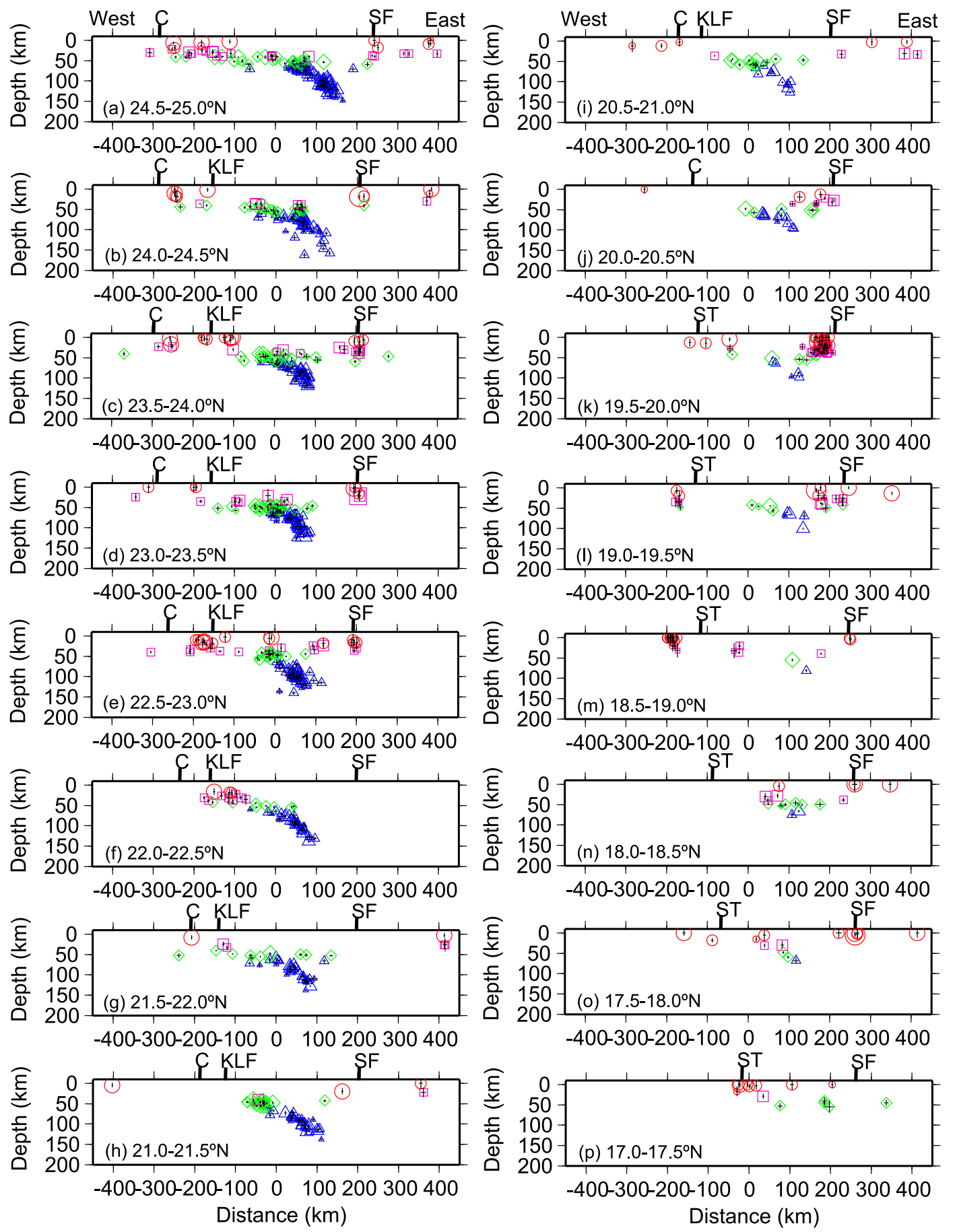

Fig. 6. East-west cross-sections of relocated earthquakes in the area shown in Fig. 5 , but north of $17^{\circ} \mathrm{N}$. Earthquakes are shown at $0.5^{\circ}$ intervals in each cross-section. Symbols depicting hypocenters are the same as those used in Fig. 5. ST: Sunda Trench, C: Chittagong Coastal Fault, KLF: Kaladan Fault, SF: Sagaing Fault.

constructed a 50-km depth contour for the entire area, and a 30-km depth contour for the northern part of the region. The contours strike approximately N-S, and show an "S" shape in map view. In the northern region $\left(25^{\circ} \mathrm{N}\right)$, the strike of the subducting Indian Plate is $\mathrm{N} 20^{\circ} \mathrm{E}$. Moving southward, the strike shows a gradual counterclockwise rotation, being approximately $\mathrm{N}-\mathrm{S}$ at $22^{\circ} \mathrm{N}$ and $\mathrm{N} 20^{\circ} \mathrm{W}$ at $20^{\circ} \mathrm{N}$. In the southern region, the strike shows a gradual clockwise rotation, attaining $\mathrm{N} 10^{\circ} \mathrm{E}$ at $17.5^{\circ} \mathrm{N}$. Since the strikes of the contour lines are almost N-S in the region between $21^{\circ} \mathrm{N}$ and $23^{\circ} \mathrm{N}$, the seismic plane is very thin in cross-sections that transect this region (Fig. 6).

The results show an increase in dip of the seismic plane with depth. The dip is $15-20^{\circ}$ at $40-60 \mathrm{~km}$ depth, but abruptly steepens below $60 \mathrm{~km}$ to a dip of $30-50^{\circ}$ at 60 $100-\mathrm{km}$ depth. The dip varies spatially, increasing from $\sim 30^{\circ}$ in the south (south of $\sim 22^{\circ} \mathrm{N}$ ) to $40^{\circ} \sim 50^{\circ}$ in the north (north of $\sim 22^{\circ} \mathrm{N}$ ). The dip also increases eastward, where it is $\sim 55^{\circ}$ at $100-140-\mathrm{km}$ depth. The maximum depth of the seismic plane is $140 \mathrm{~km}$ in the northern part; it decreases southward. The subduction earthquakes terminate at $\sim 17.5^{\circ} \mathrm{N}$, where the maximum depth of the seismic plane 

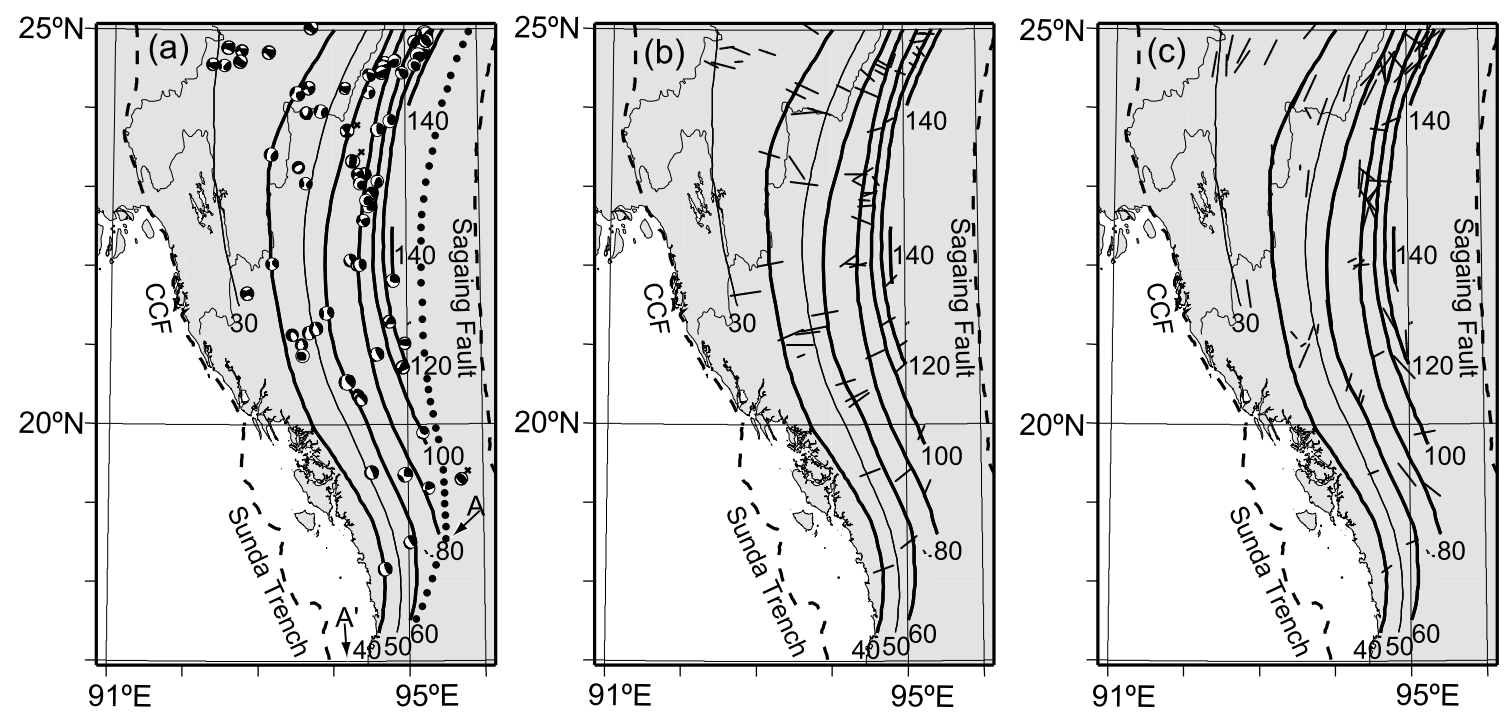

Fig. 7. Regional map showing iso-depth contours on the upper surface of the seismic plane. Numbers indicate depths (km). (a) Global CMT solutions (Dziewonski et al., 1981 and later updates) are shown for relocated earthquakes with focal depths greater than $25 \mathrm{~km}$. " $\mathrm{x}$ " indicates an earthquake that occurred outside of the slab. The dotted line shows the surface location of the leading edge of the seismic slab, as obtained by reversing the subduction of the deepest edge of the seismic slab. "A" $\left(18.7^{\circ} \mathrm{N}, 95.5^{\circ} \mathrm{E}\right)$ indicates a change in strike of the leading edge of the slab, while " $\mathrm{A}$ " $\left(17.0^{\circ} \mathrm{N}, 94.3^{\circ} \mathrm{E}\right)$ indicates the location of "A" at $10 \mathrm{Ma}$, as determined by plate reconstruction. (b) Orientation of $T$-axes of global CMT solutions shown in Fig. 7(a) except three earthquakes marked by " $x$ ". The bar length is proportional to the projection of the $T$-axis on the horizontal component. (c) The orientation of $P$-axes of global CMT solutions shown in Fig. 7(a) except three earthquakes marked by "x". The bar length is proportional to the projection of the $P$-axis on the horizontal component.

is $60 \mathrm{~km}$.

The geometry of the subducting Indian Plate obtained in this study is consistent with the previous results (Ni et al., 1989; Guzman-Speziale and Ni, 1996; Stork et al., 2008), in which the area is limited north of $19^{\circ} \mathrm{N}$ and $60 \mathrm{~km}$, or deeper, in depth. On the other hand, we have obtained contours for a wider area, $17^{\circ} \mathrm{N}-25^{\circ} \mathrm{N}$, and a wider depth range, $30 \mathrm{~km}-140 \mathrm{~km}$.

Also shown in Fig. 7(a) are global CMT solutions of earthquakes. The focal mechanisms of subduction earthquakes show a wide variation, but their $T$-axes are oriented approximately E-W and mechanisms are down-dip extension (Fig. 7(b)). This result is consistent with previous studies (e.g., Fitch, 1970; Frohlich, 2006). Figure 7(b) shows that the orientation of the $T$-axes is sub-parallel to the local dip direction of the subducting Indian Plate and perpendicular to the local strike of the contour lines. Furthermore, Figs. 7(a) and 7(b) show that the dip of the $T$-axes increase with increasing depths of earthquakes. These findings strongly support that negative buoyancy is the main driving force of these intermediate-depth earthquakes. In contrast, the strikes of $P$-axes are highly variable (Fig. 7(c)). However, the $P$-axes of earthquakes at $90-\mathrm{km}$ depth, or greater, are sub-parallel to the local strike of the subducting Indian Plate, which is consistent with the findings of a previous study by Kumar and Rao (1995), who suggested a NNEdirected stress on the subducted slab below a $90-\mathrm{km}$ depth.

In the northern part of the study area, the slope of the seismic plane is very gentle west of $94^{\circ} \mathrm{E}$ (Figs. 6 and 7), especially between $24^{\circ} \mathrm{N}$ and $25^{\circ} \mathrm{N}$ (Fig. 3). This finding is consistent with the results of Chen and Molnar (1990) from relocated earthquakes north of $23^{\circ} \mathrm{N}$, using source inversion and depth phases. Based on focal mechanism data, the authors interpreted that these earthquakes occurred within the subducting Indian Plate rather than along the plate interface. Figure 7 (c) shows that earthquakes in this area have along-strike $P$-axes.

In terms of the plate boundary at depths less than 30 $40 \mathrm{~km}$, it is difficult to determine the location of the plate boundary in the coastal region, and the Bengal Basin, because few earthquakes occur in these areas (Fig. 5), and these few earthquakes have a wide range of depths, from 0 to $50 \mathrm{~km}$ (Fig. 6).

Ni et al. (1989) determined the geometry of the WadatiBenioff zone between $20^{\circ} \mathrm{N}$ and $27^{\circ} \mathrm{N}$ in Burma. Its general trend is similar to that determined in the present study; the trend of the 100-km-depth contour is particularly similar between the two studies. However, their 60-km-depth contour coincides with our 50-km-depth contour, indicating that the dip of our model of the Wadati-Benioff zone is steeper than that reconstructed in the previous study.

\section{Subcrustal Seismic Plane above the Subducting Indian Plate}

Figure 8(a) shows the epicentral distribution of relocated earthquakes with depths less than $50 \mathrm{~km}$. In addition to seismicity along the Sagaing Fault, activity is seen east of the 60-km-depth contour. This activity is clearly seen above the subducting Indian Plate in the cross-sections shown in Figs. 8(b) and 8(c). Since these earthquakes occurred near the bottom of the seismogenic zone, or near the base of the crust within the Burma Plate, we refer to them as subcrustal earthquakes in this paper. Although many earthquakes have occurred close to, and west of, the $60-\mathrm{km}$-depth contour, these are not discussed below because we cannot be sure if they are crustal earthquakes or subduction earthquakes. The main features of this seismic activity are shown in Fig. 8, and described below. 
(a)

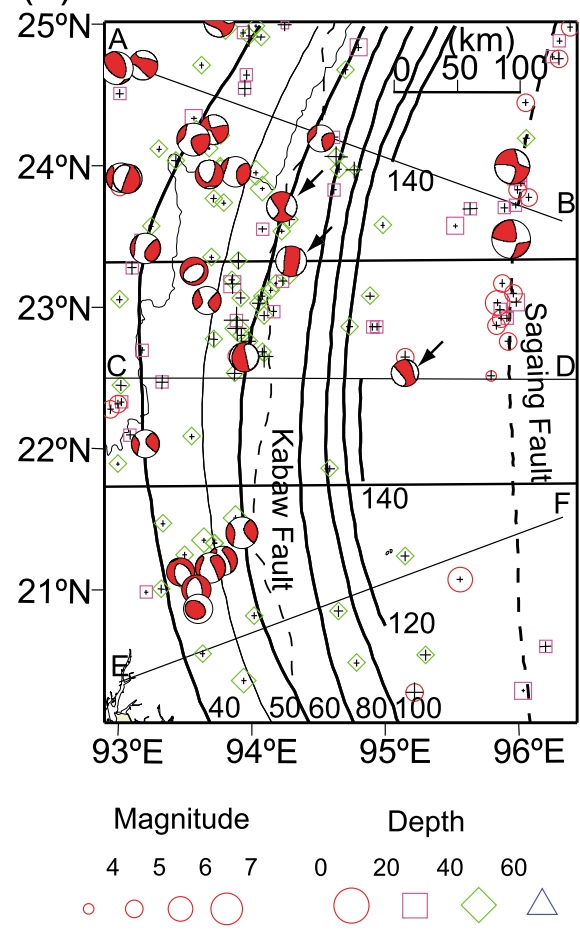

(b)
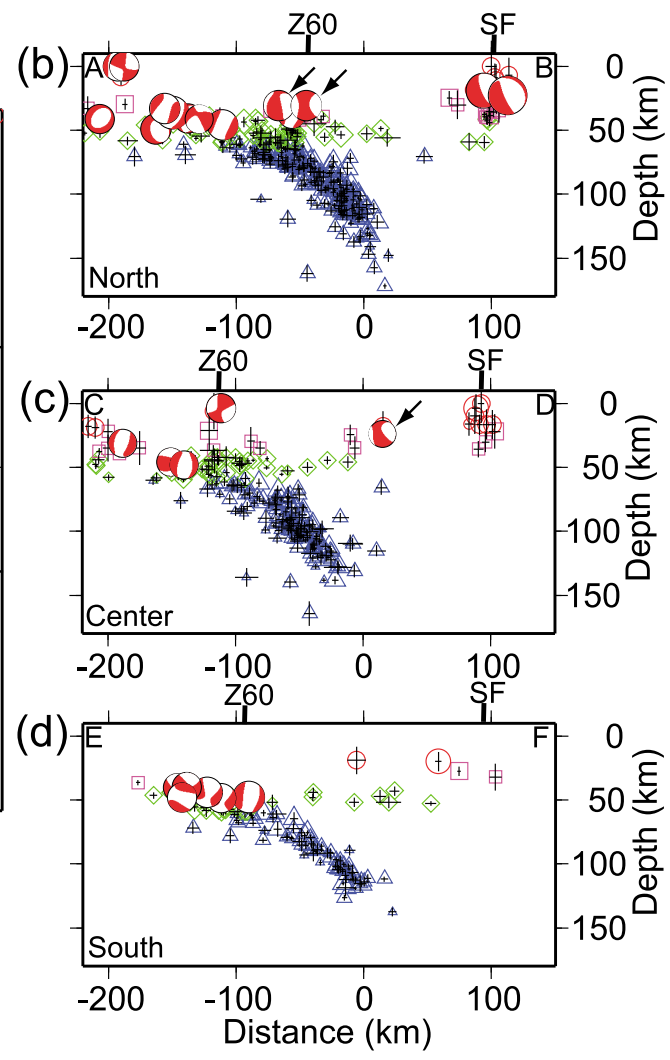

Fig. 8. (a) Map showing the distribution of shallow earthquakes with focal depths less than $50 \mathrm{~km}$. Iso-depth contours are shown for the upper surface of the seismic plane (numbers indicate depth in kilometers). (b) Cross-section along line A-B in the northern area (23.3 $\left.-25.0^{\circ} \mathrm{N}\right)$. Also shown are earthquakes at depths greater than or equal to $50 \mathrm{~km}$. (c) Cross-section along the line C-D in the central area $\left(21.7^{\circ}-23.3^{\circ} \mathrm{N}\right)$. (d) Cross-section along the line E-F in the southern area $\left(20.1^{\circ}-21.7^{\circ} \mathrm{N}\right)$. Arrows indicate subcrustal earthquakes with E-W $P$-axes. Z60: the location of the 60-km iso-depth contour. SF: Sagaing Fault.

Significant seismic activity occurs beneath the northern part of the Kabaw Fault (Figs. 8(a) and 8(b)), with focal depths generally in the range $30-50 \mathrm{~km}$. This activity elongates in a NNE-SSW direction, parallel to the local strike of the subducting plate. The activity is located about $80 \mathrm{~km}$ ESE of the 40-km-depth contour and above the $60-\mathrm{km}$ depth contour of the subducting Indian Plate. The focal mechanisms are available for three of these earthquakes. Two of which, indicated by arrows in Figs. 8(a) and 8(b), were strike-slip earthquakes with $P$-axes oriented E-W and are completely different from subduction earthquakes along the seismic plane, which have $T$-axes oriented E-W. The cross-sections (Figs. 6 and 8(b)) reveal that these earthquakes occurred at a few to $20 \mathrm{~km}$ above the subduction seismic plate. Furthermore, the locations of these earthquakes correspond to the point where the dip of the subducting Indian Plate changes from $\sim 20^{\circ}$ to $\sim 40^{\circ}$.

The activity beneath the northern part of the Kabaw Fault continues toward the ESE (Figs. 8(a) and 8(b)) as far as the Sagaing Fault. The depths of these subcrustal earthquakes range from 20 to $60 \mathrm{~km}$. Similar subcrustal activity is seen in the central area (Figs. 8(a) and 8(c)). Since the CMT solution of one of the earthquakes that occurred east of the 140-km-depth contour, which is indicated by arrows in Figs. 8(a) and 8(c), indicates strike-slip faulting with a $P$-axis oriented E-W, similar to the earthquakes in the northern area, we may consider these two areas of seismic activity together. The same type of subcrustal activity is seen in the southern area (Figs. 8(a) and 8(d)), although the activity near the $60-\mathrm{km}$-depth contour occurs at a greater depth than that in the above areas. Subcrustal activity may indicate the base of the seismogenic layer of the Burma Plate, suggesting thinning of the continental crust to the east and toward the Sagaing Fault. Therefore, the Sagaing Fault is located in an area where the cut-off depth of seismicity becomes shallower and where the strength of the crust is weaker.

The existence of a subcrustal seismic plane may help to constrain the degree of seismic coupling along the plate interface. Since the subcrustal seismic plane starts at a depth of $\sim 40 \mathrm{~km}$, the subducting Indian Plate, and the overriding Burma Plate, may be seismically coupled down to depths of $40-50 \mathrm{~km}$.

\section{Discussion}

The International Seismological Centre (2009) provided significantly improved ISC locations (EHB) using the Engdahl et al. (1998) algorithm. Although the EHB locations are quite precise as well as our MJHD locations, the number of located earthquakes in the EHB catalog is 630 , which is only $64 \%$ of ours. Furthermore, the focal depths of 174 among 630 earthquakes were fixed in the EHB catalog. We have compared our results with the EHB locations, including the focal depths. The results are as follows: There are 421 common earthquakes between our MJHD and EHB (depth free) catalogs. Differences of latitude, longitude and 
focal depth between MJHD and EHB are $0.015^{\circ} \pm 0.069^{\circ}$, $0.014^{\circ} \pm 0.077^{\circ}$ and $-7.4 \pm 12.3 \mathrm{~km}$, respectively. The comparison indicates that our focal depths are $\sim 7 \mathrm{~km}$ shallower than the focal depths of EHB on average. The increment of the number of earthquakes greatly contributed to iso-depth contours drawn at shallower depths, and the detection of subcrustal earthquakes. Since seismicity south of $20^{\circ} \mathrm{N}$ and west of $93^{\circ} \mathrm{E}$ is low, we are more confident to draw isodepth contours of the subducting plate there. Furthermore, the number of subcrustal earthquakes is very low, and only MJHD can detect them, because many subcrustal events, which we identified, were events having a fixed depth in the EHB catalog. Although the EHB method resolved the depths of intermediate-depth and deep-focus earthquakes, but not those of shallower earthquakes, because their depth phases are unclear comparing deeper events so that we think depths of some shallower events were fixed in the EHB. On the other hand, the MJHD method improved depths, regardless of focal depths, by using only reliable initial $P$ waves with a high accuracy, which were carefully selected by applying station corrections to reduce the effect of the lateral heterogeneity of the Earth.

We also compared MJHD depths with depths determined by global CMT solutions, and found that their reliability is less than the MJHD and EHB catalogs, because of the following two reasons. Firstly, the scatter of hypocenters along the seismic plane relating to the subduction is largest in the global CMT solutions. Secondly, the standard deviation of the differences of depths between global CMT and MJHD (or EHB) is double that between MJHD and EHB. This fact is consistent with the first reason. Since it is very difficult to obtain precise absolute locations using only teleseismic data, we must wait until a local network is established in Myanmar.

In terms of the precise assessment of earthquake and tsunami hazards, it is important to determine the location of the Burma subduction zone, and to study the relationship between seismic activity and fault zones in the region. Although many previous studies have obtained the geometry of the subducting Indian Plate beneath the Burma Plate (based on hypocenter distributions), these studies have assumed subduction from the inland plate boundary, north of $20^{\circ} \mathrm{N}$ (e.g., Ni et al., 1989; Guzman-Speziale and Ni, 1996; Stork et al., 2008). For example, assuming that four shallow earthquakes were interplate earthquakes, Satyabala (2003) located the plate interface and considered the Burma Arc and other thrust faults (located near the Kaladan Fault in Fig. 3) to be the boundary between the Indian and Burma Plates. However, this interpretation is inconsistent with the focal mechanisms of the four earthquakes. The mechanisms of earthquakes Nos. 11, 26, and 33 (figure 3(iv) and table 1 in the work of Satyabala (2003)) are strike-slip or thrust, with $P$-axes oriented E-W; none of the nodal planes are oriented parallel to the plate interface. Furthermore, the focal depths of three of the four earthquakes (as determined by MJHD relocation) are $0-4 \mathrm{~km}$ (events 11,26 , and 83 in figure 3(iv) and table 1 in the work of Satyabala (2003)). Therefore, these events did not occur on the plate boundary. Furthermore, Satyabala (2003) regarded earthquakes located east of the Burma Arc as outer-rise earthquakes.
However, Fig. 3(c) clearly shows two areas of seismic activity. Consequently, we should regard these earthquakes not as outer rise-earthquakes, but as both shallow crustal and subduction (western extension of intermediate-depth events) earthquakes. Stork et al. (2008) relocated 81 earthquakes precisely in the Burma arc, $21^{\circ} \mathrm{N}-27^{\circ} \mathrm{N}$, by using the JHD method (Douglas, 1967), while we relocated 980 earthquakes, which is more than 10 times as many. Therefore, we were able to delineate the subducting Indian Plate west of $93^{\circ} \mathrm{E}$ and south of $21^{\circ} \mathrm{N}$, where seismicity is low, and where Stork et al. (2008) could not include in their study. Our results have consequently revealed the detailed geometry of the subducting Indian Plate over a much wider area.

Since we precisely relocated many earthquakes, we have been able to determine the detailed interface between the subducting Indian and Burma Plates, which might be a few to $\sim 10 \mathrm{~km}$ above the seismic plane, thereby enabling an accurate understanding of the tectonics of the Burma subduction zone. Although we were able to calculate depth contours for the upper surface of the slab for regions deeper than, or equal to, $30 \mathrm{~km}$, this was not possible for shallower regions (Fig. 7). However, the plate boundary may reach the CCF (Chittagong Coastal Fault), provided that we extend the plate interface westward. Based on our results, it is difficult to assess the validity of Cummins's (2007) proposal regarding the likelihood of a tsunamigenic earthquake in the northern Bay of Bengal, along the Burma subduction zone. However, we note that the location of the fault plane of the 1762 earthquake, as proposed by Cummins (2007), is inconsistent with our plate model.

The iso-depth contours for the upper surface of the seismic slab show an "S" shape in map view (Fig. 7). What was the original shape of the seismic slab, prior to subduction? To address this question, we reconstruct the slab at the surface to determine its original shape, which is useful for plate reconstructions. Fixing the $40-\mathrm{km}$ iso-depth contour as a standard, we raised the deepest edge of the seismic slab, which is its leading edge. The result is shown by the dotted line in Fig. 7(a). The strike of the leading edge shows an abrupt change at Point $\mathrm{A}\left(18.7^{\circ} \mathrm{N}, 95.5^{\circ} \mathrm{E}\right)$ in Fig. $7(\mathrm{a})$, from $\sim \mathrm{N}-\mathrm{S}$ north of the point to $\mathrm{N} 20^{\circ} \mathrm{E}$ south of the point.

We reconstructed the location of the subducted seismic slab beneath the Burma Plate at $10 \mathrm{Ma}$, when the movement direction of the Indian Plate relative to the Eurasia Plate changed, probably due to anchoring in the Hindu Kush (Lee and Lawver, 1995). The India-Eurasia collision caused a clockwise rotation of the Burma-Andaman arc, a westward migration of the Burmese arc, and then the trend of the arc would have gradually assumed a more NS direction (Karig et al., 1979). Consequently, the resultant eastward component of the plate motion would have become considerably reduced, finally culminating in the cessation of subduction, or highly oblique subduction, in recent times (e.g., Rao and Kumar, 1999; Satyabala, 2003; Nielsen et al., 2004; Rao and Kalpna, 2005; Stork et al., 2008). The present rate and direction of convergence of the Indian Plate relative to the Burma Plates are currently $23 \mathrm{~mm} / \mathrm{yr}$ and $\mathrm{N} 35^{\circ} \mathrm{E}$, respectively (Socquet et al., 2006). The bend at Point A $\left(18.7^{\circ} \mathrm{N}, 95.5^{\circ} \mathrm{E}\right)$ approached the Sunda trench at Point $\mathrm{A}^{\prime}$ 
$\left(17.0^{\circ} \mathrm{N}, 94.3^{\circ} \mathrm{E}\right)($ Fig. $7(\mathrm{a}))$, where the strike of the Sunda trench shows an abrupt change from $\sim \mathrm{N} 20^{\circ} \mathrm{E}$ in the south to $\sim \mathrm{N} 25^{\circ} \mathrm{W}$ in the north (Figs. 1 and 5). South of Point A, the strike of the reconstructed leading edge is sub-parallel to the strike of the present Sunda trench, possibly indicating that this southern boundary of the subducting Indian Plate was a transform fault until $10 \mathrm{Ma}$. There exists low seismicity along the plate boundary at $17^{\circ} \mathrm{N}-14^{\circ} \mathrm{N}$, and the trench axis is sub-parallel to the relative plate motion. Therefore, this leading edge $\left(\mathrm{A}-\mathrm{A}^{\prime}\right)$ may have been a transform-type plate boundary at $10 \mathrm{Ma}$.

Intermediate-depth earthquakes do not occur at the south of the "S" shape seismic slab, that is the area between the Andaman Islands and Myanmar (e.g., Rajendran and Gupta, 1989; Guzman-Speziale and Ni, 1996), reflecting the fact that the plate boundary is oriented parallel to the relative plate motion (Sinvhal et al., 1978). Engdahl et al. (2007) relocated earthquakes for the period 1918-2005, including aftershocks of the 2004 Sumatra Andaman earthquake. The northern end of the high-seismicity area is around $15^{\circ} \mathrm{N}$ for both background seismicity and the aftershocks of the 2004 event. No deep earthquakes were observed between $15^{\circ} \mathrm{N}$ and $17^{\circ} \mathrm{N}$ (Fig. 5). Therefore, as the extension of the present plate boundary at $15^{\circ}-17^{\circ} \mathrm{N}$, the southern edge of the present seismic slab (south of point "A" in Fig. 7(a) at $17^{\circ}-18.5^{\circ} \mathrm{N}$ ) is subducting beneath the Burma Plate.

We have distinguished crustal earthquakes from subduction earthquakes. The most significant feature of crustal earthquakes is the seismicity along the Sagaing Fault (Figs. 5 and 8). Many crustal earthquakes were well located along the Sagaing Fault. The largest earthquake analyzed in this study was the $M_{\mathrm{w}} 6.9$ earthquake of 5 January, 1991. This mainshock, and its two immediate aftershocks, were relocated on the Sagaing Fault. Therefore, this $M_{\mathrm{w}} 6.9$ earthquake was a right-lateral strike-slip earthquake that occurred along the Sagaing Fault, with a northward rupture propagation.

The Kabaw Fault is one of the most important active faults in Myanmar. West of the fault is the Indo-Burmese Wedge (IBW) (also known as the Arakan Range or Arakan Yoma) as far as the Arakan trench; east of the fault is the Myanmar Central Basin (MCB) (also known as the Central Lowland) as far as the Sagaing Fault (e.g., Le Dain et al., 1984; Nielsen et al., 2004; Socquet et al., 2006; Maurin and Rangin, 2009). There occurs little seismicity along and around the Kabaw Fault. One crustal earthquake (20 November, 1980, $M_{\mathrm{w}}$ 5.2) was located $\sim 20 \mathrm{~km}$ west of the Kabaw Fault, clearly distinct from subcrustal earthquakes (Figs. 8(a) and 8(c)). The MJHD focal depth of this earthquake is $3.7 \pm 7.0 \mathrm{~km}$, while the global CMT and ISC depths are 20.0 and $30 \mathrm{~km}$, respectively. This earthquake had a thrust mechanism with a $P$-axis oriented E-W, consistent with the nature of the Kabaw Fault and completely different from intermediate-depth earthquakes in surrounding areas (see Fig. 8(a)), which have $T$-axes oriented E-W and record down-dip extension.

The Indo-Burmese Wedge (IBW) is a site of diffuse strain partitioning, comprising right-lateral shearing in the innermost part, and E-W shortening in the outermost part; the E-W compression is currently active (e.g., Le Dain et al.,
1984; Maurin and Rangin, 2009). Crustal seismicity in the IBW is active relative to that in the surrounding areas (Fig. 5), which is consistent with the occurrence of active crustal deformation in the IBW. In particular, seismicity around the Kaladan Fault toward the CCF is active north of $21.5^{\circ} \mathrm{N}$ (Figs. 2 and 5). This area corresponds to the central part of the IBW (Maurin and Rangin, 2009). The large variety of focal mechanisms obtained for this area indicates a complex stress field.

Figure 3(c) shows the clear distinction between crustal earthquakes and subduction earthquakes in the study area. The positioning of nearby stations in India (see Fig. 4) means that the hypocenters in Fig. 3(c) are precisely determined. Therefore, we can conclude that the subducting Indian Plate exists at least near the CCF on land. Two crustal earthquakes that occurred between the CCF and the Kaladan Fault north of $24.5^{\circ} \mathrm{N}$ show strike-slip faulting with $P$-axes oriented N-S, while two nearby earthquakes (between $92^{\circ} \mathrm{E}$ and $93^{\circ} \mathrm{E}$ ) show reverse faulting with $P$-axes oriented E-W, similar to the characteristics of an earthquake that occurred near the Kabaw Fault.

Although some studies have suggested that subduction is no longer active along the Arakan trench based on earthquake mechanisms (e.g., Le Dain et al., 1984; Rao and Kumar, 1999), our results are consistent with active oblique subduction based on improved GPS measurements and marine surveys (e.g., Nielsen et al., 2004; Socquet et al., 2006). Estimating a pole for the India-Burma plate pair, Gahalaut and Gahalaut (2007) considered a major rightlateral strike motion between the India-Burma plates in the northern Indo-Burmese Arc region. However, if we consider a $30-\mathrm{km}$ iso-depth contour running NS there, the movement between the India-Burma plates is still oblique there as in the southern Indo-Burmese Arc region.

\section{Conclusions}

Since ISC and USGS hypocenters do not enable the Burma subduction zone to be precisely determined, we have relocated earthquakes in, and around, Myanmar for the period 1964-2007 using the modified joint hypocenter determination (MJHD) method developed by Hurukawa and Imoto $(1990,1992)$. Twelve sub-regions were selected for the relocations of earthquakes. A total of 980 earthquakes were well relocated. Hypocenters determined using the MJHD method are much more precise than those determined by ISC and USGS, enabling crustal earthquakes to be distinguished from subduction earthquakes.

We have identified two groups of earthquake hypocenter distributions, in addition to crustal earthquakes: (1) intermediate-depth earthquakes related to the subduction of the Indian Plate beneath the Burma Plate; and (2) subcrustal earthquakes at the base of the continental crust. The main features of these groups are described below.

Firstly, we have constructed iso-depth contours (for depths of $40-140 \mathrm{~km}$ ) for the subduction earthquakes caused by the subducting Indian Plate beneath the Burma Plate, in the region of $17^{\circ} \mathrm{N}-25^{\circ} \mathrm{N}$, thereby revealing its geometry. The upper surface of the subducting Indian Plate might be situated a few to $\sim 10 \mathrm{~km}$ above these contours. We also constructed the $30-\mathrm{km}$-depth contour for the area 
north of $21.5^{\circ} \mathrm{N}$. The iso-depth contours strike approximately N-S and show an "S" shape in map view. The strike of the subducting plate is $\mathrm{N} 20^{\circ} \mathrm{E}$ at $25^{\circ} \mathrm{N}$; south from here, the strike rotates counterclockwise to $\mathrm{N} 20^{\circ} \mathrm{W}$ at $20^{\circ} \mathrm{N}$, then rotates clockwise to $\mathrm{N} 10^{\circ} \mathrm{E}$ at $17.5^{\circ} \mathrm{N}$, where slab earthquakes cease to occur. We were unable to obtain depth contours for regions shallower than $30 \mathrm{~km}$ because of the lack of earthquakes at these depths. The mechanisms of subduction earthquakes are down-dip extension, with $T$-axes oriented sub-parallel to the local dip of the slab.

Secondly, we have observed subcrustal earthquakes at the base of the Burma Plate, above the subducting Indian Plate. Focal depths for these earthquakes are $\sim 20-50 \mathrm{~km}$. The CMT solutions for three of these earthquakes indicate strike-slip faulting with $P$-axes oriented E-W. The mechanisms indicate a stress field of E-W compression in the overriding Burma Plate. This activity may represent the base of the seismogenic layer within the Burma Plate and suggest thinning of the continental crust to the east and toward the Sagaing Fault. Therefore, the Sagaing Fault is located at an area where the cut-off depth of seismicity becomes shallower and the strength of the crust is weaker.

Acknowledgments. We thank Prof. H. Gupta and an anonymous reviewer for their helpful comments during review. Figures and maps were prepared using Generic Mapping Tools software (Wessel and Smith, 1998).

\section{References}

Chen, W. P. and P. Molnar, Source parameters of earthquakes and intraplate deformation beneath the Shillong plateau and the northern Indoburma ranges, J. Geophys. Res., 95, 12527-12552, 1990.

Cummins, P. R., The potential for giant tsunamigenic earthquakes in the northern Bay of Bengal, Nature, 449, doi:10.1038/nature06088, 2007.

DeMets, C., R. G. Gordon, D. F. Argus, and S. Stein, Effect of recent revisions to the geomagnetic reversal time scale on estimates of current plate motions, Geophys. Res. Lett., 21, 2191-2194, 1994.

Dewey, J. W., Seismicity and tectonics of western Venezuela, Bull. Seismol. Soc. Am., 62, 1711-1751, 1972.

Douglas, A., Joint epicenter determination, Nature, 215, 47-48, 1967.

Dziewonski, A. M., T.-A. Chou, and J. Woodhouse, Determination of earthquake source parameters from waveform data for studies of global and regional seismicity, J. Geophys. Res., 86, 2825-2852, 1981.

Engdahl, E. R., R. van der Hilst, and R. Buland, Global teleseismic earthquake relocation with improved travel times and procedures for depth determination, Bull. Seismol. Soc. Am., 88, 722-743, 1998.

Engdahl, E. R., A. Villasenor, H. R. DeShon, and C. H. Thurber, Teleseismic relocation and assessment of seismicity (1918-2005) in the region of the $2004 M_{\mathrm{w}} 9.0$ Sumatra-Andaman and $2005 M_{\mathrm{w}} 8.6$ Nias Island Great Earthquakes, Bull. Seismol. Soc. Am., 97, S43-S61, doi:10.1785/0120050614, 2007.

Fitch, T. J., Earthquake mechanisms in the Himalayan, Burmese, and Andaman regions and continental tectonics in central Asia, J. Geophys. Res., 75, 2699-2709, 1970.

Freedman, H. W., A statistical discussion of $\mathrm{P}$ residuals from explosions, Part 2, Bull. Seismol. Soc. Am., 57, 545-561, 1967.

Frohlich, C., Deep Earthquakes, Cambridge Univ. Press, Cambridge, 2006.

Gahalaut, V. K. and K. Gahalaut, Burma plate motion, J. Geophys. Res., 112, B10402, doi:10.1029/2007JB004928, 2007.

Gupta, H. and V. Gahalaut, Is the northern Bay of Bengal tsunamigenic?, Bull. Seismol. Soc. Am., 99, 3496-3501, doi:10.1785/0120080379, 2009.

Guzman-Speziale, M. and J. F. Ni, Seismicity and active tectonics of the western Sunda arc, in The Tectonic Evolution of Asia, edited by A. Yin and T. M. Harrison, pp. 63-84, Cambridge Univ. Press, New York, 1996.
Hurukawa, N., Quick aftershock relocation of the 1994 Shikotan earthquake and its fault planes, Geophys. Res. Lett., 22, 3159-3162, 1995.

Hurukawa, N. and M. Imoto, Fine structure of an underground boundary between the Philippine Sea and Pacific Plates beneath the Kanto district, Japan, Zisin (J. Seismol. Soc. Jpn.), 43, 413-429, 1990 (in Japanese with an English abstract).

Hurukawa, N. and M. Imoto, Subducting oceanic crust of the Philippine Sea and Pacific plates and weak-zone-normal compression in Kanto district, Japan, Geophys. J. Int., 109, 639-652, 1992.

Hurukawa, N. and P. M. Maung, Two seismic gaps on the Sagaing Fault, Myanmar, derived from relocation of historical earthquakes since 1918, Geophys. Res. Lett., 38, L01310, doi:10.1029/2010GL046099, 2011.

International Seismological Centre, EHB Bulletin, http://www.isc.ac.uk, Internatl. Seis. Cent., Thatcham, United Kingdom, 2009.

Karig, D. E., S. Suparka, G. F. Moore, and P. E. Hehanussa, Structure and Cenozoic evolution of the Sunda arc in the central Sumatra region, Mem. Amm. Assoc. Pet. Geol., 29, 223-237, 1979.

Kumar, M. R. and N. P. Rao, Significant trends related to the slab seismicity and tectonics in the Burmese arc region from Harvard CMT solutions, Phys. Earth Planet. Inter., 90, 75-80, 1995.

Le Dain, A. Y., P. Tapponnier, and P. Molnar, Active faulting and tectonics of Burma and surrounding regions, J. Geophys. Res., 89, 453-472, 1984.

Lee, T. Y. and L. A. Lawver, Cenozoic plate reconstruction of southeast Asia, Tectonophysics, 251, 85-138, 1995.

Maurin, T. and C. Rangin, Structure and kinematics of the Indo-Burmese Wedge: Recent and fast growth of the outer wedge, Tectonics, 28, TC2010, doi:10.1029/2008TC002276, 2009.

Ni, J. F., M. Guzman-Speziale, M. Bevis, W. E. Holt, T. C. Wallace, and W. R. Seager, Accretionary tectonics of Burma and the three-dimensional geometry of the Burma subduction zone, Geology, 17, 68-71, 1989.

Nielsen, C., N. Chamot-Rooke, C. Rangin, and the Andaman Cruise Team, From partial to full strain partitioning along the Indo-Burmese hyperoblique subduction, Mar. Geol., 209, 303-327, 2004.

Rajendran, K. and H. K. Gupta, Seismicity and tectonic stress field of a part of the Burma-Andaman-Nicobar arc, Bull. Seismol. Soc. Am., 79, 989-1005, 1989.

Rao, N. P. and Kalpna, Deformation of the subducted Indian lithospheric slab in the Burmese arc, Geophys. Res. Lett., 32, L05301, doi:10.1029/2004GL022034, 2005.

Rao, N. P. and M. R. Kumar, Evidences for cessation of Indian plate subduction in the Burmese arc region, Geophys. Res. Lett., 26, 31493152, 1999.

Satyabala, S. P., Oblique plate convergence in the Indo-Burma (Myanmar) subduction region, Pure Appl. Geophys., 160, 1611-1650, 2003.

Sinvhal, H., K. N. Khattri, K. Rai, and V. K. Gaur, Neo-tectonics and timespace seismicity of the Andaman-Nicobar region, Bull. Seismol. Soc. Am., 68, 399-409, 1978.

Smith, E. G. C., An efficient algorithm for routine joint hypocenter determination, Phys. Earth Planet. Inter., 30, 135-144, 1982.

Socquet, A., C. Vigny, N. Chamot-Rooke, W. Simons, C. Rangin, and B. Ambrosius, India and Sunda plates motion and deformation along their boundary in Myanmar determined by GPS, J. Geophys. Res., 111, B05406, doi:10.1029/2005JB003877, 2006.

Stork, A. L., N. D. Selby, R. Heyburn, and M. P. Searle, Accurate relative earthquake hypocenters reveal structure of the Burma subduction zone, Bull. Seismol. Soc. Am., 98, 2815-2827, doi:10.1785/0120080088, 2008.

Tun, P. P., Hypocenter relocation and moment tensor analysis of earthquakes in Myanmar: Toward the investigation of the Burma subductionSagaing fault system, Master thesis, National Graduate Institute for Policy Studies and Building Research Institute, Tsukuba, Japan, 2008.

Vigny, C., A. Socquet, C. Rangin, N. Chamot-Rooke, M. Pubellier, M. Bouin, G. Bertrand, and M. Becker, Present-day crustal deformation around Sagaing fault, Myanmar, J. Geophys. Res., 108(B11), 2533, doi:10.1029/2002JB001999, 2003.

Wessel, P. and W. H. F. Smith, New, improved version of the Generic Mapping Tools released, Eos Trans. AGU, 79, 579, 1998.

N. Hurukawa (e-mail: hurukawa@kenken.go.jp), P. P. Tun, and B. Shibazaki 